\title{
INTERCULTURAL SENSITIVITY IN ENGLISH DEPARTMENT STUDENTS OF AN INDONESIAN HIGHER EDUCATION INSTITUTION
}

\author{
Syarifuddin Dollah \\ Universitas Negeri Makassar, Indonesia \\ Email: syarifuddindollah@unm.ac.id \\ Amirullah Abduh \\ Universitas Negeri Makassar, Indonesia \\ Email: amirullah@unm.ac.id \\ Ahmad Talib \\ Universitas Negeri Makassar, Indonesia \\ Email:ahmadtalib@unm.ac.id
}

\begin{abstract}
This study aimed at identifying intercultural sensitivity elements perceived by English department students in an Indonesian university. Broadly, this study used mix-methods: quantitative and qualitative data. Quantitative data were obtained through questionnaires. The questionnaires were sent to 100 participants and followed by semi-structured interview of 10 participants. For this paper, only quantitative data were used. The findings show that there were three important intercultural sensitivity dimensions: cultural engagement, respect to cultural differences and interaction enjoyment. This study contributes to the more understanding of intercultural dimensions and debates across the globe about intercultural issues. In addition, this study provides methodological contribution on the set of criteria to determine the scale of intercultural sensitivity. This study has further implication of the teaching and learning as one of the key elements on English curriculum. The study suggested that the research on wider participants can further enhance the sounding of this findings and provide overarching understanding of intercultural sensitivity.
\end{abstract}

Keywords: Intercultural Sensitivity, English Education, Higher Education

\section{INTRODUCTION}

Most current research in English language education focused on generic understanding own and cultures, and culture and identity. Few studies have investigated intercultural sensitivity in English language education. Most research have been conducted in the areas of non-English department within western contexts. For this reason, intercultural sensitivity is important to further investigate.

A number of studies have indicated the importance of intercultural sensitivity. Chen and Starosta (2000) pointed out that people with intercultural sensitive mind and behavior tend to successfully adapt with people from different cultural and ethnic backgrounds. Similarly, Byram (1997) commented that it is important for people are equipped with intercultural communication competence to help them sensitive to other cultures.

In Indonesia, research was conducted in several areas. In the areas of socio-cultural and language learning (Abduh \& Rosmaladewi, 2017b), collaborative culture of learning (Rosmaladewi \& Abduh, 2017), intercultural and online vocabulary learning (Abduh \& Rosmaladewi, 2017a), imagined 
identities and intercultural investment (Abduh \& Andrew, 2017), cultural and ideological values (Abduh \& Saud, 2017) and analyzing language and cultural values in Indonesian language policy (Dollah, Abduh, \& Rosmaladewi, 2017). Among these investigations, intercultural sensitivity has not become the main focus. Therefore, this paper aims to fill this gap by examining students' intercultural sensitivity beliefs particularly in English department of higher education.

\section{LITERATURE REVIEW}

Chen and Starosta (2000) describes intercultural dimension into three categories: intercultural awareness, intercultural adroitness and intercultural sensitivity. The intercultural awareness relates to an individual capability to decipher similar and different culture of others. This means that those peoples in this category tends to have broader knowledge of cultures other than their own. The awareness of other cultures reflects the cognitive ability of a person in their expressions and in the way they about others.

Intercultural adroitness is the observable behavior of interculturality (Chen \& Starosta, 2000). This competence reflects what a person behave and perform in a multicultural environment. This refers to person's ability to have meaningful communication with people from other cultures. The dimension contains four components: message skills, appropriate self-disclosure, behavioral flexibility, and interaction management (Chen \& Starosta, 2000).

Intercultural sensitivity is the psychological and emotional dimensions of intercultural communication competence (Chen \& Starosta 2000). This psychological trait brings about the emotional feeling and desire of an individual to acknowledge that every person is different, to appreciate that there are similarities and differences among human beings, and to accept the dissimilarities of culture, ethnic, and identities. Intercultural sensitivity includes self-confidence, self-monitoring, inclusiveness, empathy, broadminded, and social dimensions. In addition, the main feature of intercultural sensitivity to further explore in this research are cultural engagement, respect to cultural differences, and interaction enjoyment.

In language teaching, it is described as intercultural communicative competence (Byram, 1997; Lo Bianco et al. 1999; Sercu, 2002). A research has been conducted to grasp intercultural scholars' perceptions of intercultural competence, however there is no common agreement on what intercultural understanding is (Deardorff, 2006). Despite these differences, those researchers have indicated that the term "intercultural" becomes an important aspect of teaching and learning. Therefore, this paper argues that intercultural sensitivity has to be part of the core curriculum and become compulsory additional outside classroom activities.

\section{METHODOLOGY}

The research employed a pragmatic paradigm which combines both quantitative and qualitative approach. The quantitative approach used open-ended questionnaire, and the qualitative data were gained from semistructured interviews. The questionnaire was created via google form and sent it out to 100 teachers, however only half of them filled the questionnaire due to technical internet connection problems. The questionnaire consists of 26 items. It was adapted from Chen and Starosta (2000) and 2 items were added by researchers. The data were analysed using descriptive statistics. For the purpose of this article, only quantitative data were reported.

To assess intercultural sensitivity, researchers established criteria that are used to identify the score level of sensitivity in relation to cultural engagement. 
- $\quad 0-1.5$ : Poorly sensitive to intercultural issues

- 1.6-2.5: Fairly sensitive to intercultural issues

- 2.6-3.5: Highly sensitive to intercultural issues

- 3.6-above: Very highly sensitive to intercultural issues

We also created a set of criteria to assess respect others and interaction enjoyment as follows:

- $0-1.5$ : Very highly sensitive to intercultural issues

- 1.6-2.5: Highly sensitive to intercultural issues

- 2.6-3.5: Fairly sensitive to intercultural issues

- 3.6-above: Poorly sensitive to intercultural issues

\section{FINDINGS AND DISCUSSION \\ Profile of Participants}

The participants of this study mostly comes from female which constitutes more than $50 \%$ of the respondents (See Figure 1), while male only less than $50 \%$ of the participants.

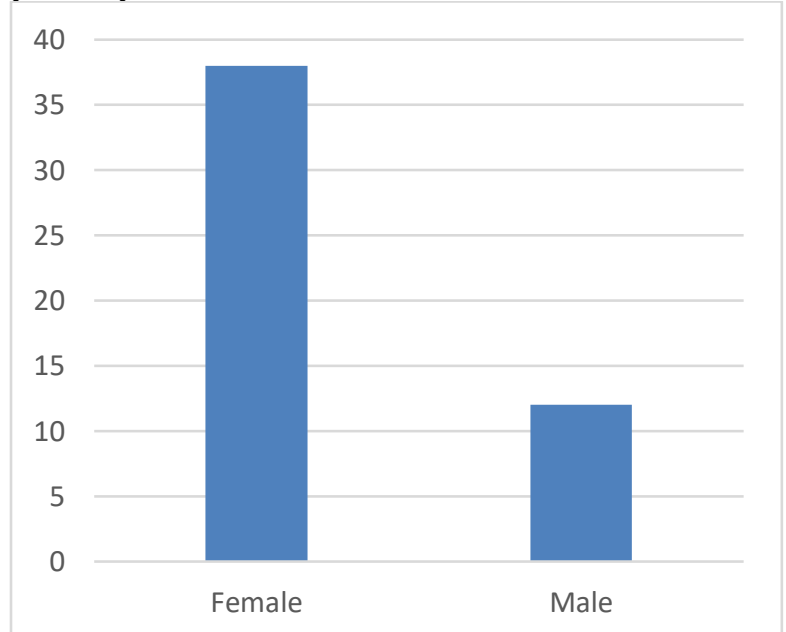

Figure 1: Participants' gender background

In relation to age, there were various age backgrounds of the participant in this study (see Figure 2). There was roughly balance between age of 18-25 and above 26 years. Only small number of participants aged under 17 and above 35 years of age.

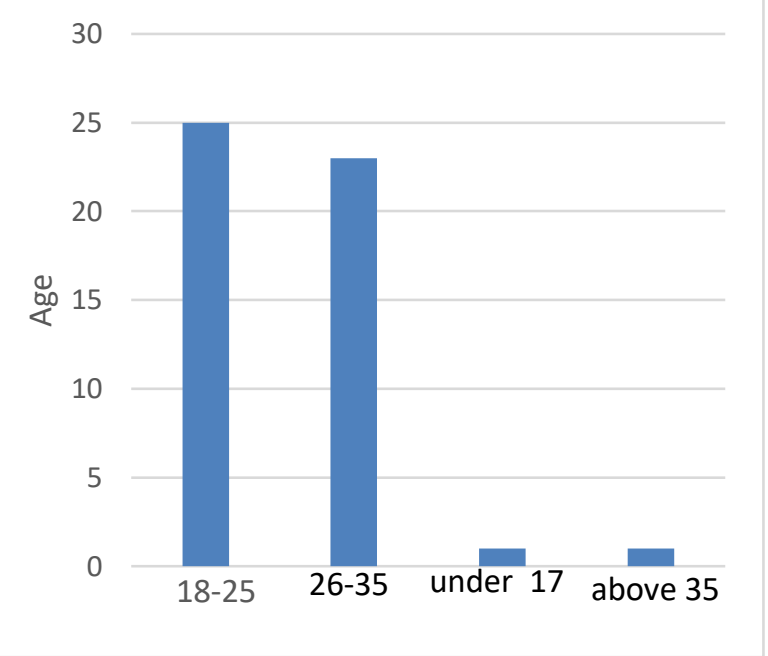

Figure 2: Participant's age

In relation to educational background, participants at this study comprise of three levels of qualifications (see Table 3). 39\% of participants was in bachelor degree, $20 \%$ of master's degree, and $41 \%$ of them was doctoral students. This shows a variety of educational levels of students participating at this study.

\section{Bachelor Master Doctorate}

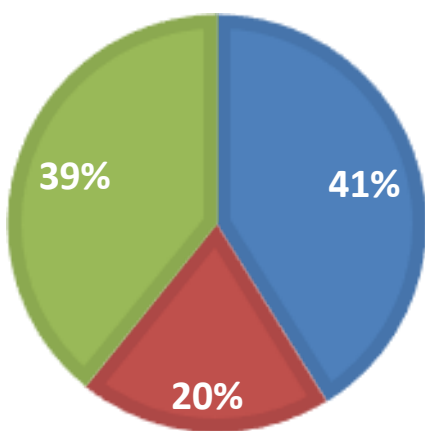

Figure 3. Participants' educational background

\section{Intercultural Sensitivity Dimension} Cultural engagement

This graph (Figure 4) reflects that participants in this study enjoyed interacting 
with people from different cultures (4.26). They tended to wait before forming an impression of culturally-distinct counterparts (3.18). Participants were very inclusive to the people from other cultures (4.14). In addition, they treat others positively in all circumstances (3.92) and tended to behave and talk to others in a friendly way (2.48), and respected different verbal and non-verbal signs of communication (3.8)

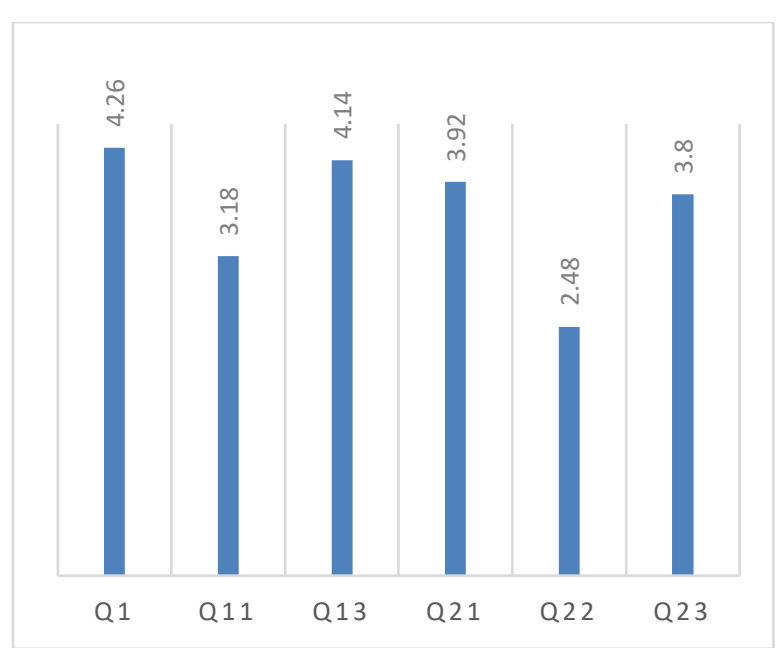

Figure 4: Cultural Engagement

The graph means that they enjoyed interacting with people from different cultures, open-minded to people from different cultures, gave positive responses to my culturally different counterpart during our interaction and had a feeling of enjoyment towards differences between my culturallydistinct counterpart and me. The average score was more 2.6 which is highly sensitive to interculturalism.

\section{Respect to cultural differences}

Participants in this study (see Figure 5) think that they were not narrow minded and tended to enjoy talking and walking with people from different cultures. In addition, they respected the values of people from different cultures (1.8), they mostly accepted the opinions from people of different cultures
(1.6). They did not think they were superior from others (2.5).

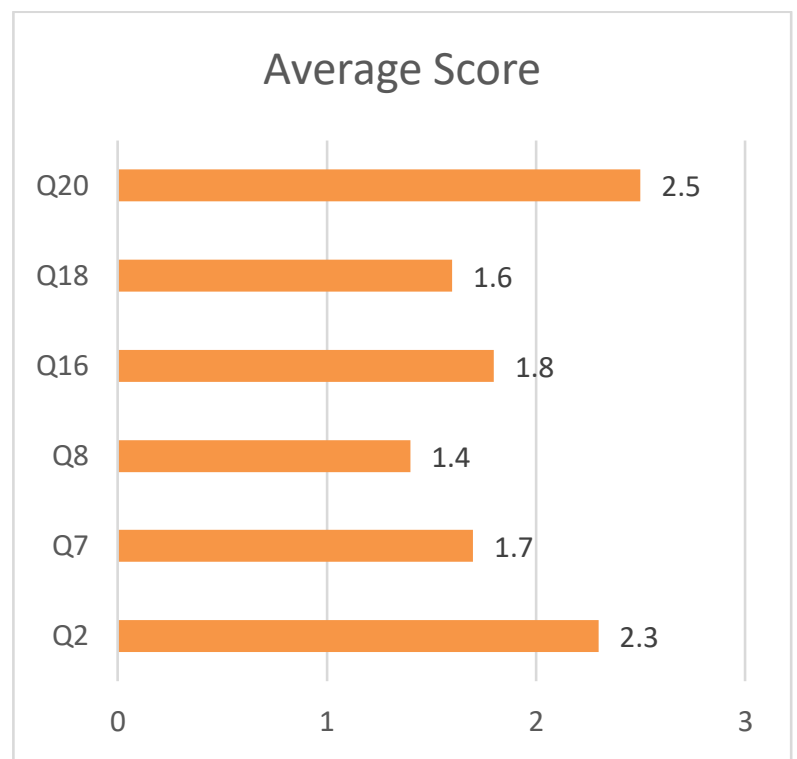

Figure 5: Respect to cultural differences

The graph indicates that the lower the score the better of the participant achieve: The better they behave and respect to intercultural issues.

\section{Interaction enjoyment}

Figure (6) below indicates the interaction enjoyment of participants with other cultures. Participants did not get upset easily when interacting with people from different cultures. They were enthusiastic when they were with people from different cultures. Finally, they often felt useful when interacting with people from different cultures.

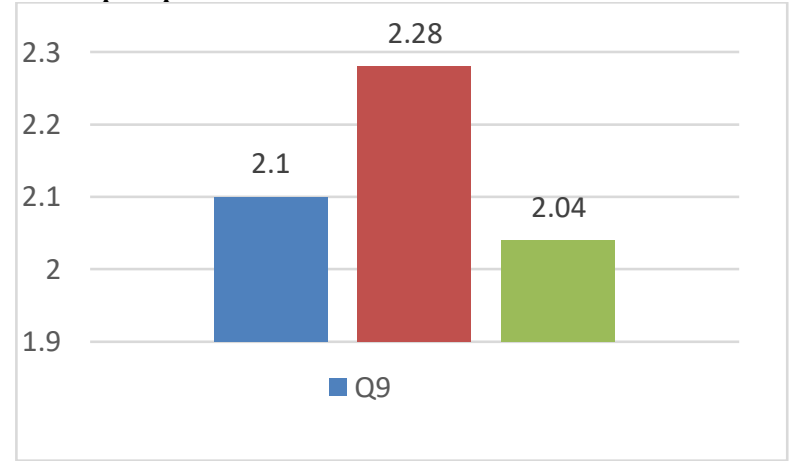

Figure 6: Interaction enjoyment 
This confirms what Chen and Starosta' s (2000) argument that the lower the average score, the more they enjoy interact with people from cultures other than their own.

\section{CONCLUSION AND LIMITATION}

From the analysis of the findings, it appears that participants in this study show highly sensitive and understanding to other cultures in terms of cultural engagement, respect of cultural differences and interaction enjoyment. Both cognitively and emotionally, participants in this study are able to engage with people from culture other their own. They have established more respectful minded to others and keen to take part in communication with those from other cultures. Despite they are more intercultural minded, it is important to observe how these intercultural dimensions are practiced and realized within a multicultural setting. The limitation of this study is that these findings are based on student's perceptions, not their behaviors. Therefore, it is important to conduct further research and observation on students' practical behavior when they interact with other students or other people from different cultures. It is recommended that research that involve wider stakeholders such as curriculum developer, lecturers, trainers and policy makers on intercultural issues may contribute to better and overarching understanding of intercultural sensitivity.

\section{REFERENCES}

Abduh, A., \& Andrew, M. (2017). Investment and Imagined Identities of Biliterate Indonesian Lecturers: An Exploratory Case Study. International Journal of Indonesian Studies, 1(4), 1-13. Retrieved from http://artsonline.monash.edu.au/indonesia n-studies-journal/ijis-4-2017/

Abduh, A., \& Rosmaladewi, R. (2017a). Taking the Lextutor on-line tool to examine students' vocabulary level in business English students. World Transactions on Engineering and Technology Education, 15(3), 283-286.

Abduh, A., \& Rosmaladewi, R. (2017b). The socio-cultural learning in an Indonesian Polytechnic. In A. A. Gaffar, T. Aryanti, A. Setiawan, \& M. Alias (Eds.), Regionalization and harmonization in tvet (pp. 145-148).

Abduh, A., \& Saud, S. (2017). Ideology in Indonesian language policies. In Advances in Social Science, Education and Humanities Research (ASSEHR), 2nd International Conference on Education, Science, and Technology (ICEST 2017) Ideology (Vol. 149, pp. 10-12). Atlantis Press. Retrieved from http://www.atlantis-

press.com/proceedings/icest-17/25884890

Byram, M. (1997). Teaching and assessing intercultural communicative competence, Channel View Books.

Chen, G.-M. and W. J. Starosta (2000). "The Development and Validation of the Intercultural Sensitivity Scale." Human Communication, 3, 1-15

Deardorff, D. K. (2006). "Identification and assessment of intercultural competence as a student outcome of internationalization." Journal of studies in international education 10 (3): 241-266.

Dollah, S., Abduh, A., \& Rosmaladewi, R. (2017). Benefits and Drawbacks of NVivo QSR Application. In Advances in Social Science, Education and Humanities Research (ASSEHR), Proceedings of the 2nd International Conference on Education, Science, and Technology (ICEST 2017) (Vol. 149, pp. 61-63). Atlantis Press. Retrieved from http://www.atlantis-

press.com/proceedings/icest17/25884907.

Lo Bianco, J., A. J. Liddicoat, et al. (1999). Striving for the Third Place: Intercultural 
Competence through Language Education, ERIC.

Rosmaladewi, R., \& Abduh, A. (2017). Collaborative Teaching Cultures of English Lecturers in Indonesian Polytechnics. International Journal of Language Education, 1(1), pp 20-28. Retrieved from http://ojs.unm.ac.id/index.php/ijole/article /view/2868.

Sercu, L. (2002). "Autonomous learning and the acquisition of intercultural communicative competence: Some implications for course development." Language Culture And Curriculum 15(1): 61-74.

\section{Appendix}

Adapted Intercultural sensitivity scale (Chen \& Starosta, 2000)

Name:

Age:

Sex: M/F

\section{Intercultural Sensitivity Scale}

Below is a series of statements concerning intercultural communication. There are no right or wrong answers. Please work quickly and record your first impression by indicating the degree to which you agree or disagree with the statement. This scale should be completed before and after the spring academy. Please fill it in and send it right away.

5: Strongly agree, 4: agree, 3: neutral, 2: disagree, 1: strongly disagree

Thank you for your cooperation.

1. I enjoy interacting with people from different cultures.

2. I think people from other cultures are narrow-minded.

3. I am pretty sure of myself in interacting with people from different cultures.

4. I find it very hard to talk in front of people from different cultures.

5. I always know what to say when interacting with people from different cultures.

6. I can be as sociable as I want to be when interacting with people from different cultures.

7. I don't like to be with people from different cultures.
8. I respect the values of people from different cultures.

9. I get upset easily when interacting with people from different cultures.

10. I feel confident when interacting with people from different cultures.

11. I tend to wait before forming an impression of culturally-distinct counterparts.

12. I often get discouraged when I am with people from different cultures.

13. I am open-minded to people from different cultures.

14. I am very observant when interacting with people from different cultures.

15. I often feel useless when interacting with people from different cultures.

16. I respect the ways people from different cultures behave

17. I try to opt different cultures in as much information as I can when interacting with people from people from different cultures.

18. I would not accept the opinions from people of different cultures

19. I am sensitive to my culturally-distinct counterpart's subtle meanings during our

interaction.

20. I think my culture is better than other cultures.

21. I often give positive responses to my culturally different counterpart during our

interaction.

22. I avoid those situations where I will have to deal with culturally-distinct persons.

23. I often show my culturally-distinct counterpart my understanding through verbal or nonverbal cues.

24. I have a feeling of enjoyment towards differences between my culturallydistinct counterpart and me.

25. I acknowledge similarities between my culture and others.

26. I always think and behave positively to other people from different cultures.

27. I learn and recognize my cultures before I learn other cultures. 